\title{
Comparison between RECIST and PERCIST criteria in therapeutic response assessment in cases of lymphoma
}

\author{
Marwa Mohammed Hasan Tawfik, Ahmed Mohamed Monib, Aya Yassin and Susan Adil Ali*
}

\begin{abstract}
Background: Accurate radiologic assessment of treatment response in lymphomas is important for helping the clinicians to properly evaluate effectiveness of treatment and consequently guide therapeutic management of these patients. Imaging tools based on anatomic response are suboptimal in detecting functional changes in tumors resulting after early effective treatment. Recently, with the development of ${ }^{18}$ F-FDG PET/CT, both functional and anatomic information has been integrated for assessing treatment response in both solid tumors and hematologic malignancies. The aim of this study was to compare therapeutic response in lymphoma patients using both RECIST 1.1 and PERCIST 1.0 criteria.

Results: Among the included 33 lymphoma patients, RECIST 1.1 and PERCIST 1.0 classifications of therapeutic response were concordant in 20 patients $(60.6 \%)$ and discordant in 13 patients (39.4\%), with a tendency of RECIST 1.1 to downgrade the tumor response in $12 / 13$ patients ( $P$ value $<0.001$ ).

Conclusion: The recently applied PERCIST 1.0 is efficient and more accurate than RECIST 1.1 to assess treatment response in lymphoma patients, which is subsequently affecting further management of these patients.
\end{abstract}

Keywords: Hodgkin lymphoma, Non-Hodgkin lymphoma, ${ }^{18}$ F FDG PET/CT, RECIST, PERCIST

\section{Background}

Lymphomas show different response to treatment rather than other solid tumors. Post-therapeutic residual lesions are frequently detected in both non-Hodgkin and Hodgkin lymphomas. Lymphomatous masses often do not regress completely after therapy because of necrotic debris and residual fibrosis [1]. Anatomic response criteria in lymphoma patients often underestimate the chemotherapeutic effect [2]. The currently accepted standard anatomic response classifications are Response evaluation criteria in solid tumor (RECIST) and RECIST 1.1; however, they do not have the ability to detect functional changes in tumors resulting after early effective treatment [3]. ${ }^{18} \mathrm{~F}$-Fluorodeoxyglucose $\left({ }^{18} \mathrm{~F}\right.$-FDG) positron emission tomography/computed tomography (PET/

*Correspondence: dr.susanadil@hotmail.com

Radiodiagnosis Department, Ain Shams University, Cairo, Egypt
CT) is a hybrid imaging modality which allows simultaneous metabolic and anatomical imaging of tumors during a single diagnostic session [4-7]. Assessments of treatment response of different cancers with ${ }^{18}$ F-FDG $\mathrm{PET} / \mathrm{CT}$ can be obtained with high efficiency and tumor tracer uptake is expected to decline over time. So, it is important to report the change in standardized uptake value (SUV) in initial and follow-up scans as the PET biologic predictive value of PET is much greater than that of anatomic studies [8-10]. This is done by using PET response criteria in solid tumor (PERCIST criteria) depending on standardized uptake value changes by the tumoral mass [11]. Aim of this work was to compare between anatomical post-therapeutic response by contrast-enhanced CT with applied RECIST 1.1 criteria and combined qualitative and quantitative metabolic response by ${ }^{18} \mathrm{~F}$-FDG PET/CT with applied PERCIST 1.0 criteria in lymphoma patients.

\section{Springer Open}

(- The Author(s). 2020 Open Access This article is licensed under a Creative Commons Attribution 4.0 International License, which permits use, sharing, adaptation, distribution and reproduction in any medium or format, as long as you give appropriate credit to the original author(s) and the source, provide a link to the Creative Commons licence, and indicate if changes were made. The images or other third party material in this article are included in the article's Creative Commons licence, unless indicated otherwise in a credit line to the material. If material is not included in the article's Creative Commons licence and your intended use is not permitted by statutory regulation or exceeds the permitted use, you will need to obtain permission directly from the copyright holder. To view a copy of this licence, visit http://creativecommons.org/licenses/by/4.0/. 
Table 1 RECIST 1.1 and PERCIST 1.0 criteria used for therapeutic response evaluation

\begin{tabular}{|c|c|c|}
\hline & RECIST 1.1 & PERCIST 1.0 \\
\hline \multirow[t]{2}{*}{ Responders } & CR Disappearance of target lesions & $\begin{array}{l}\text { CMR The target lesion shows absent FDG uptake or shows SUL } L_{\text {peak }} \text { less } \\
\text { than that of the liver }\end{array}$ \\
\hline & $\begin{array}{l}\mathrm{PR} \geq 30 \% \text { decrease in the sum of the diameter of the } \\
\text { target lesions }\end{array}$ & $\mathbf{P M R} \geq 30 \%$ decrease or at least $0.8 \mathrm{SUL}_{\text {peak }}$ decrease \\
\hline \multirow{2}{*}{$\begin{array}{l}\text { Non- } \\
\text { responders }\end{array}$} & SD Increase in size $<20 \%$ or decrease size $<30 \%$ & SMD Increase or decrease in the SUL peak of less than $30 \%$ \\
\hline & $\begin{array}{l}\text { PD } \geq 20 \% \text { increase in the sum of the diameter of the } \\
\text { target lesions or newly developed lesions }\end{array}$ & $\begin{array}{l}\text { PMD The target lesion shows an increase in } S U L_{\text {peak }}>30 \% \text { or at least } 0.8 \\
\text { SUL }\end{array}$ \\
\hline
\end{tabular}

\section{Methods}

\section{Patients}

Our prospective study was conducted in the period between September 2018 and January 2020. Thirty three patients with biopsy-proven lymphoma (including both Hodgkin and Non-Hodgkin types) who were referred to perform baseline pre-treatment and end of therapy PET/ CT imaging studies were enrolled in this study. Approval of the institutional review board and written informed consents from all patients were obtained before the start of this study.

\section{Inclusion criteria}

Any patient presented with lymphoma who did not receive any therapy, aged 18 years or older with no sex predilection were included.

\section{Exclusion criteria}

Any patient showing normal initial study or with concomitant malignancy, patients known to have contraindications for radiation (e.g., pregnant females), patients with renal impairment or had high blood glucose levels at the time of the study, and patients who underwent any surgical intervention or received radiotherapy as a line of treatment were excluded.

Table 2 Different pathological types and subtypes of the study population

\begin{tabular}{lll}
\hline & Pathology & No. of patients \\
\hline Types & NHL & $15(45.5 \%)$ \\
& HL & $17(51.5 \%)$ \\
Subtypes & GALT & $1(3.0 \%)$ \\
& NHL-DLBCL & $12(36.4 \%)$ \\
& NHL-TCL & $1(3 \%)$ \\
& NHL-F & $2(6 \%)$ \\
& HL-NS & $10(30.3 \%)$ \\
& HL-MC & $5(15.2 \%)$ \\
& HL-LP & $2(6 \%)$ \\
GALT & $1(3 \%)$ \\
\hline
\end{tabular}

\section{Patient preparation}

Procedure time was 2 weeks after the end of chemotherapy. Patients were fasting for a minimum of $6 \mathrm{~h}$ before the scan with good hydration. Exercises were avoided for a minimum of $2 \mathrm{~h}$ (ideally $48 \mathrm{~h}$ ) before the scan. Kidney function tests were reviewed and confirmed to be within normal limit with pre-scanning blood glucose level estimation (accepted between 150 and $200 \mathrm{mg} / \mathrm{dL}$ ) and administration of antecubital intravenous cannula.

\section{Technique of ${ }^{18} \mathrm{~F}$-FDG PET/CT scan}

The radioactive tracer $\left({ }^{18} \mathrm{~F}-\mathrm{FDG}\right)$ was injected intravenously in a dose of $0.06-0.08 \mathrm{mCi} / \mathrm{kg}$ body weight. All patients were kept in a warm temperature room and asked

Table 3 Baseline tumor characteristics in the study population

\begin{tabular}{|c|c|c|}
\hline & Lymphoma characteristics & No. of patients \\
\hline \multicolumn{3}{|l|}{ Location } \\
\hline \multirow[t]{3}{*}{ Nodal } & Absent & $4(12.1 \%)$ \\
\hline & Supra & $15(45.5 \%)$ \\
\hline & Supra \& infra & $14(42.4 \%)$ \\
\hline \multirow[t]{11}{*}{ Extra-nodal } & Absent & $16(48.5 \%)$ \\
\hline & Splenic & $7(21.2 \%)$ \\
\hline & Oropharyngeal & $2(6.1 \%)$ \\
\hline & Splenic \& hepatic & $1(3.0 \%)$ \\
\hline & Hepatic \& renal & $1(3.0 \%)$ \\
\hline & Gastric \& hepatic & $1(3.0 \%)$ \\
\hline & Splenic \& renal & $1(3.0 \%)$ \\
\hline & Parapharyngeal & $1(3.0 \%)$ \\
\hline & Parotid & $1(3.0 \%)$ \\
\hline & Lung & $1(3.0 \%)$ \\
\hline & Bone & $1(3.0 \%)$ \\
\hline \multirow[t]{7}{*}{ Stage } & । & $2(6.1 \%)$ \\
\hline & $\mathrm{IE}$ & $1(3.0 \%)$ \\
\hline & $\|$ & $11(33.3 \%)$ \\
\hline & \|E & $1(3.0 \%)$ \\
\hline & III & $5(15.2 \%)$ \\
\hline & IIIS & $7(21.2 \%)$ \\
\hline & IV & $6(18.2 \%)$ \\
\hline
\end{tabular}


Table 4 Correlation between tumor size and CT-based therapeutic response in the study population

\begin{tabular}{|c|c|c|c|c|c|c|c|}
\hline & \multicolumn{4}{|c|}{ Therapeutic response by RECIST } & \multirow{2}{*}{$\begin{array}{l}\text { Test } \\
\text { value\# }\end{array}$} & \multirow{2}{*}{$\begin{array}{l}\boldsymbol{P} \\
\text { value }\end{array}$} & \multirow[t]{2}{*}{ Sig. } \\
\hline & $C R$ & PR & SD & PD & & & \\
\hline \multicolumn{8}{|l|}{ Base (sum) } \\
\hline Median (IQR) & $35(22.5-46.75)$ & $69.5(47.5-95)$ & $35(17-39.7)$ & 77.5 (33.75-136.5) & 7.821 & 0.050 & S \\
\hline Range & $7.5-63$ & $8.5-125$ & 17-39.7 & $3.5-182$ & & & \\
\hline \multicolumn{8}{|l|}{ End (sum) } \\
\hline Median (IQR) & $0(0-0)$ & $28.5(6.2-36.5)$ & $29(16.8-37)$ & $26.5(13-61)$ & 16.771 & 0.001 & HS \\
\hline Range & $0-0$ & $1-78$ & $16.8-37$ & 0-95 & & & \\
\hline \multicolumn{8}{|c|}{ Tumor reduction (\%) } \\
\hline Median (IQR) & $100(100-100)$ & $65.5(52-76)$ & $6(0.01-17)$ & $59(47-70)$ & 22.206 & 0.000 & HS \\
\hline Range & $100-100$ & $31-91$ & $0.01-17$ & $47-70$ & & & \\
\hline
\end{tabular}

$P$ value $>0.05$ Non-significant (NS), $P$ value $<0.05$ Significant (S), $P$ value $<0.01$ Highly significant (HS)

\# Kruskal-Wallis test

to rest without vigorous activity and void just before imaging. Scanning by a hybrid PET/CT scanner (Discovery IQ five-ring machine class I IPX0 used with 16 slices of CT, GE [General Electric Company], Milwaukee, WI, USA, 2016) was performed $60 \mathrm{~min}$ after injection. The patient was positioned supine on the table. Initial singlephase contrast material-enhanced helical CT was performed following injection of $125 \mathrm{~mL}$ of a lowosmolarity iodinated contrast medium (Optiray 350) at a rate of $4 \mathrm{~mL} / \mathrm{s}$ by using a power injector. A whole body CT study (from the head to mid-thigh) scanning was obtained using $110 \mathrm{~mA}, 110 \mathrm{kV}, 0.5 \mathrm{~s}$ tube rotation time, and 3.3-mm section thickness. After CT scanning, PET scan covering the same field of view was obtained

Table 5 Correlation between disease characteristics and CT-based therapeutic response in the study population

\begin{tabular}{|c|c|c|c|c|c|c|c|}
\hline & \multicolumn{4}{|c|}{ Objective response by RECIST } & \multirow{3}{*}{$\begin{array}{l}\text { Test } \\
\text { value* }\end{array}$} & \multirow{3}{*}{$\begin{array}{l}\boldsymbol{P} \\
\text { value }\end{array}$} & \multirow[t]{3}{*}{ Sig. } \\
\hline & $\overline{C M R}$ & PMR & SMD & PMD & & & \\
\hline & No. $=8$ & No. $=18$ & No. $=3$ & No. $=4$ & & & \\
\hline \multicolumn{8}{|l|}{ Pathology } \\
\hline $\mathrm{NHL}$ & $3(37.5 \%)$ & $9(50.0 \%)$ & $0(0.0 \%)$ & $3(75.0 \%)$ & 5.435 & 0.489 & NS \\
\hline HL & $5(62.5 \%)$ & $8(44.4 \%)$ & $3(100.0 \%)$ & $1(25.0 \%)$ & & & \\
\hline GALT & $0(0.0 \%)$ & $1(5.6 \%)$ & $0(0.0 \%)$ & $0(0.0 \%)$ & & & \\
\hline \multicolumn{8}{|l|}{ Location } \\
\hline NA & $1(12.5 \%)$ & $2(11.1 \%)$ & $0(0.0 \%)$ & $1(25.0 \%)$ & 10.530 & 0.104 & NS \\
\hline Supra & $6(75.0 \%)$ & $5(27.8 \%)$ & $3(100.0 \%)$ & $1(25.0 \%)$ & & & \\
\hline Supra \& infra & $1(12.5 \%)$ & $11(61.1 \%)$ & $0(0.0 \%)$ & $2(50.0 \%)$ & & & \\
\hline \multicolumn{8}{|l|}{ Stage } \\
\hline I & $1(12.5 \%)$ & $1(5.6 \%)$ & $0(0.0 \%)$ & $0(0.0 \%)$ & 26.203 & 0.095 & NS \\
\hline IE & $1(12.5 \%)$ & $0(0.0 \%)$ & $0(0.0 \%)$ & $0(0.0 \%)$ & & & \\
\hline II & $4(50.0 \%)$ & $4(22.2 \%)$ & $3(100.0 \%)$ & $0(0.0 \%)$ & & & \\
\hline IIE & $1(12.5 \%)$ & $0(0.0 \%)$ & 0 (0.0\%) & $0(0.0 \%)$ & & & \\
\hline III & $0(0.0 \%)$ & $3(16.7 \%)$ & $0(0.0 \%)$ & 2 (50.0\%) & & & \\
\hline IIIS & $1(12.5 \%)$ & 6 (33.3\%) & 0 (0.0\%) & 0 (0.0\%) & & & \\
\hline IV & 0 (0.0\%) & $4(22.2 \%)$ & 0 (0.0\%) & $2(50.0 \%)$ & & & \\
\hline \multicolumn{8}{|l|}{ New lesion } \\
\hline Absent & $8(100.0 \%)$ & 18 (100\%) & $3(100.0 \%)$ & 0 (0.0\%) & 33.000 & 0.000 & HS \\
\hline Present & $0(0.0 \%)$ & $0(0.0 \%)$ & $0(0.0 \%)$ & $4(100.0 \%)$ & & & \\
\hline
\end{tabular}

$P$ value $>0.05$ Non significant (NS), $P$ value $<0.05$ Significant (S), $P$ value $<0.01$ Highly significant (HS) 
Table 6 Correlation between tumor SUL $L_{\text {peak }}$ and PET-based therapeutic response in the study population

\begin{tabular}{|c|c|c|c|c|c|c|c|}
\hline & \multicolumn{4}{|c|}{ Objective response by PERCIST } & \multirow{3}{*}{$\begin{array}{l}\text { Test } \\
\text { value\# }\end{array}$} & \multirow{3}{*}{$\begin{array}{l}\boldsymbol{P} \\
\text { value }\end{array}$} & \multirow[t]{3}{*}{ Sig. } \\
\hline & \multirow{2}{*}{$\begin{array}{l}\text { CMR } \\
\text { No. }=18\end{array}$} & \multirow{2}{*}{$\begin{array}{l}\text { PMR } \\
\text { No. }=9\end{array}$} & \multirow{2}{*}{$\begin{array}{l}\text { SMD } \\
\text { No. }=2\end{array}$} & \multirow{2}{*}{$\begin{array}{l}\text { PMD } \\
\text { No. }=4\end{array}$} & & & \\
\hline & & & & & & & \\
\hline \multicolumn{8}{|l|}{ Base SUL } \\
\hline Median (IQR) & $9.1(4.7-14)$ & $12.3(7.3-16)$ & $12.75(5.5-20)$ & $10.4(6.15-12)$ & 1.185 & 0.757 & NS \\
\hline Range & $2-29.3$ & $4.7-21.7$ & $5.5-20$ & $3.5-12$ & & & \\
\hline \multicolumn{8}{|l|}{ End SUL } \\
\hline Median (IQR) & $0(0-0)$ & $2.8(2.6-3.7)$ & $13.64(6.28-21)$ & $3.47(1.32-5.45)$ & 24.085 & 0.000 & HS \\
\hline Range & $0-1.4$ & $2.2-8.9$ & $6.28-21$ & $0-6.6$ & & & \\
\hline \multicolumn{8}{|c|}{ Uptake reduction (\%) } \\
\hline Median (IQR) & $100(100-100)$ & $56(44-75)$ & $0(0-0)$ & $54.5(34.5-82)$ & 27.310 & 0.000 & HS \\
\hline Range & $100-100$ & $37-89$ & $0-0$ & $24-100$ & & & \\
\hline
\end{tabular}

$P$ value $>0.05$ Non significant (NS), $P$ value $<0.05$ Significant (S), $P$ value $<0.01$ Highly significant (HS)

\# Kruskal-Wallis test

immediately. Six to seven bed positions are planned in the three-dimensional acquisition mode for scanning the entire patient with 3-5-min acquisition at each bed position. Images were transferred to a dedicated workstation to be reconstructed and displayed in axial, coronal, and sagittal planes.

\section{Image analysis}

Images were analyzed by two experienced radiologists having five and seven years' experience in PET/CT imaging. Analysis of CT images was done by visual inspection with selection of target lesions and measuring their dimensions. Analysis of PET/CT images was done by

Table 7 Correlation between disease characteristics and PET-based therapeutic response in the study population

\begin{tabular}{|c|c|c|c|c|c|c|c|}
\hline & \multicolumn{4}{|c|}{ Objective response by PERCIST } & \multirow{3}{*}{$\begin{array}{l}\text { Test } \\
\text { value* }\end{array}$} & \multirow{3}{*}{$\begin{array}{l}\boldsymbol{P} \\
\text { value }\end{array}$} & \multirow[t]{3}{*}{ Sig. } \\
\hline & \multirow{2}{*}{$\begin{array}{l}\text { CMR } \\
\text { No. }=18\end{array}$} & \multirow{2}{*}{$\begin{array}{l}\text { PMR } \\
\text { No. }=9\end{array}$} & \multirow{2}{*}{$\begin{array}{l}\text { SMD } \\
\text { No. }=2\end{array}$} & \multirow{2}{*}{$\begin{array}{l}\text { PMD } \\
\text { No. }=4\end{array}$} & & & \\
\hline & & & & & & & \\
\hline \multicolumn{8}{|l|}{ Pathology } \\
\hline $\mathrm{NHL}$ & $10(55.6 \%)$ & $1(11.1 \%)$ & $1(50.0 \%)$ & $3(75.0 \%)$ & \multirow[t]{3}{*}{7.894} & \multirow[t]{3}{*}{0.246} & \multirow[t]{3}{*}{ NS } \\
\hline HL & 7 (38.9\%) & $8(88.9 \%)$ & $1(50.0 \%)$ & $1(25.0 \%)$ & & & \\
\hline GALT & $1(5.6 \%)$ & $0(0.0 \%)$ & $0(0.0 \%)$ & $0(0.0 \%)$ & & & \\
\hline \multicolumn{8}{|l|}{ Location } \\
\hline NA & $3(16.7 \%)$ & $0(0.0 \%)$ & $0(0.0 \%)$ & $1(25.0 \%)$ & \multirow[t]{3}{*}{3.900} & \multirow[t]{3}{*}{0.690} & \multirow[t]{3}{*}{ NS } \\
\hline Supra & $7(38.9 \%)$ & $6(66.7 \%)$ & $1(50.0 \%)$ & $1(25.0 \%)$ & & & \\
\hline Supra \& infra & $8(44.4 \%)$ & $3(33.3 \%)$ & $1(50.0 \%)$ & $2(50.0 \%)$ & & & \\
\hline \multicolumn{8}{|l|}{ Stage } \\
\hline I & $1(5.6 \%)$ & $1(11.1 \%)$ & $0(0.0 \%)$ & $0(0.0 \%)$ & \multirow[t]{7}{*}{14.506} & \multirow[t]{7}{*}{0.696} & \multirow[t]{7}{*}{ NS } \\
\hline IE & $1(5.6 \%)$ & $0(0.0 \%)$ & $0(0.0 \%)$ & $0(0.0 \%)$ & & & \\
\hline II & $5(27.8 \%)$ & $5(55.6 \%)$ & $1(50.0 \%)$ & $0(0.0 \%)$ & & & \\
\hline IIE & $1(5.6 \%)$ & $0(0.0 \%)$ & $0(0.0 \%)$ & $0(0.0 \%)$ & & & \\
\hline III & $2(11.1 \%)$ & $1(11.1 \%)$ & $0(0.0 \%)$ & $2(50.0 \%)$ & & & \\
\hline IIIS & $5(27.8 \%)$ & 1 (11.1\%) & $1(50.0 \%)$ & 0 (0.0\%) & & & \\
\hline IV & $3(16.7 \%)$ & 1 (11.1\%) & $0(0.0 \%)$ & $2(50.0 \%)$ & & & \\
\hline \multicolumn{8}{|l|}{ New lesion } \\
\hline Absent & $18(100.0 \%)$ & 9 (100.0\%) & $2(100.0 \%)$ & 0 (0.0\%) & \multirow[t]{2}{*}{33.00} & \multirow[t]{2}{*}{0.000} & \multirow[t]{2}{*}{ HS } \\
\hline Present & $0(0.0 \%)$ & $0(0.0 \%)$ & $0(0.0 \%)$ & 4 (100.0\%) & & & \\
\hline
\end{tabular}

$P$ value $>0.05$ Non significant (NS), $P$ value $<0.05$ Significant (S), $P$ value $<0.01$ Highly significant (HS) 
Table 8 Comparison between RECIST 1.1 and PERCIST 1.0-based therapeutic response assessment in the study population

\begin{tabular}{|c|c|c|c|c|c|c|c|c|}
\hline & \multicolumn{5}{|c|}{ Treatment response by RECIST 1.1} & \multirow{2}{*}{$\begin{array}{l}\text { Test } \\
\text { value* }\end{array}$} & \multirow{2}{*}{$\begin{array}{l}\boldsymbol{P} \\
\text { value }\end{array}$} & \multirow[t]{2}{*}{ Sig } \\
\hline & $\overline{C R}$ & PR & SD & PD & $\overline{\text { Total }}$ & & & \\
\hline \multicolumn{9}{|c|}{ Treatment response by PERCIST 1.0} \\
\hline CMR & $8(100.0 \%)$ & $10(55.6 \%)$ & $0(0 \%)$ & $0(0 \%)$ & 18 & 46.139 & 0.00 & HS \\
\hline PMR & $0(0 \%)$ & 7 (38.9\%) & $2(66.7 \%)$ & $0(0 \%)$ & 9 & & & \\
\hline SMD & $0(0 \%)$ & $1(5.6 \%)$ & $1(33.3 \%)$ & $0(0 \%)$ & 2 & & & \\
\hline PMD & $0(0 \%)$ & $0(0 \%)$ & $0(0 \%)$ & $4(100 \%)$ & 4 & & & \\
\hline Total & 8 & 18 & 3 & 4 & 33 & & & \\
\hline
\end{tabular}

$P$ value $>0.05$ Non significant (NS), $P$ value $<0.05$ Significant $(\mathrm{S}), P$ value $<0.01$ Highly significant (HS)

${ }^{*}$ Chi-square test

visual inspection, comparing PET and CT data, viewing fused PET/CT images, and quantitative calculation of FDG uptake corrected to lean body mass $\left(\mathrm{SUL}_{\text {peak }}\right)$. They used PERCIST 1.0 criteria on PET/CT interpretation and RECIST 1.1 criteria on CT interpretation (Table 1).

\section{Statistical analysis}

Analysis of data was done using SPSS (Statistical package for social science) program version 23. To describe the studied sample, quantitative data were presented as minimum, maximum, mean, and standard deviation. Qualitative data were presented as count and percentage. The chi-square statistic is used for testing relationships between categorical variables. The Wilcoxon signedrank test is a non-parametric statistical hypothesis test used to compare two related samples, matched samples, or repeated measurements on a single sample to assess whether their population mean ranks differ (i.e., it is a paired difference test). One-way analysis of variance (ANOVA) test was used to compare parametric quantitative data between more than two groups.

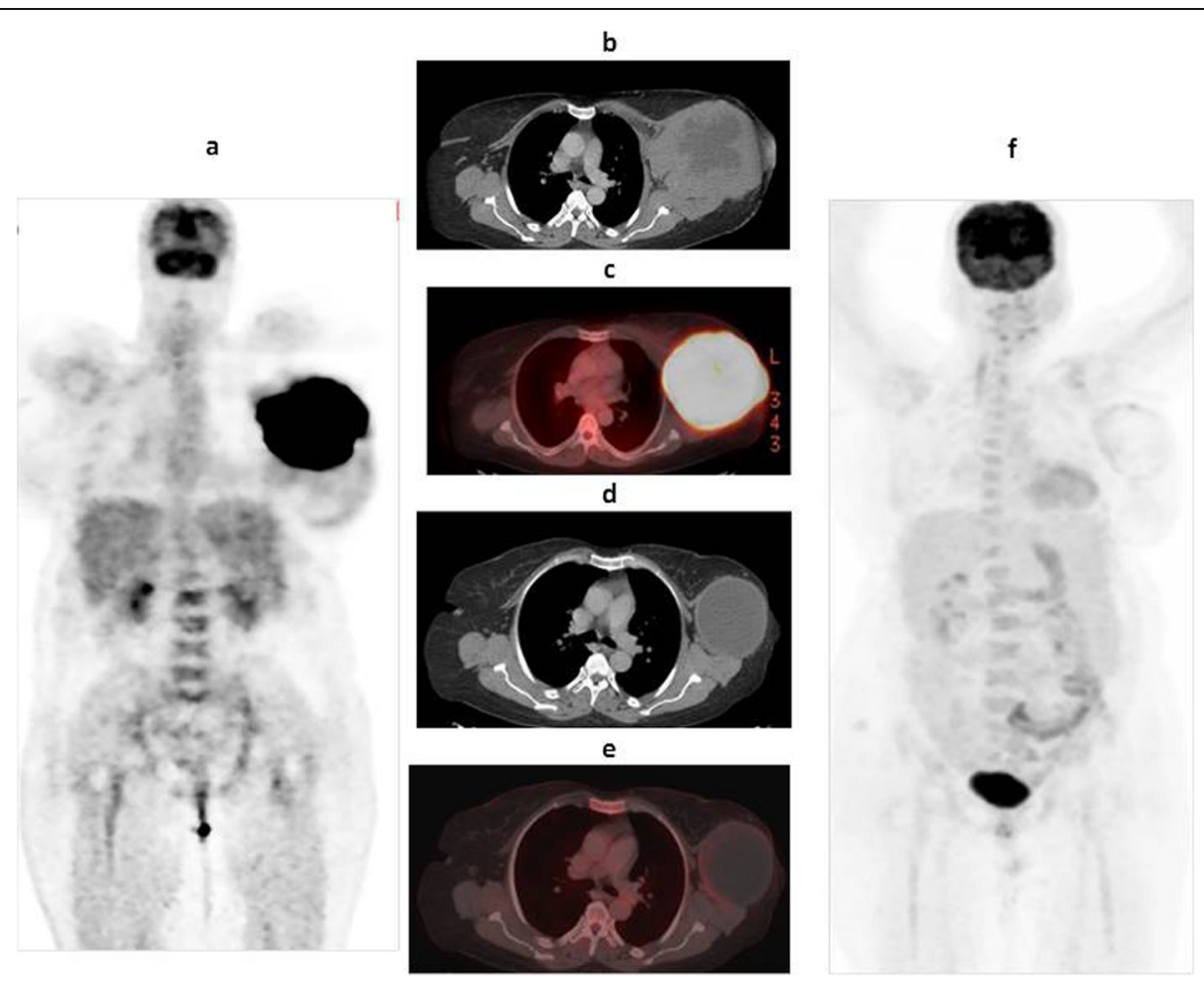

Fig. 1 A 51-year-old female patient, recently diagnosed case of NHL (large B cell type). Initial PET/CT study revealed large hypermetabolic mass at the left axilla and axillary tail of left breast in whole body PET MIP image (a), measuring about $16 \times 16 \times 15 \mathrm{~cm}$ with central breaking down in axial CECT image (b) and achieving 19 SUL peak in corresponding fused PET/CT image (c). Follow-up PET/CT study revealed smaller metabolically inactive lesion in whole body PET MIP image (f) that measured $10 \times 9.5 \times 9.3 \mathrm{~cm}$ in axial CECT image (d) denoting PR according to RECIST 1.1 , yet showing no FDG uptake in corresponding fused PET/CT image (e) denoting CMR according to PERCIST 1.0 
Kruskal-Wallis test was used to compare nonparametric quantitative data between different groups.

\section{Results}

The study included 33 patients (24 females and 9 males) ranged in age from 18 to 85 years with mean age of $41.91 \pm 16.63$ years. Fifteen patients presented with histopathologically proven non-Hodgkin lymphoma, 17 patients had Hodgkin lymphoma, and 1 patient with Gutassociated lymphoid tissue (GALT). The most presented pathological subtype was NHL-DLBCL (36.4\%) and HLNS (30.3\%), the rest of presented data are summarized in Table 2.

At baseline staging (Table 3), most of the patients were of stages II and III (representing 72.7\%). Sixteen patients showed only nodal disease (48\%), 13 patients showed both nodal and extra-nodal disease, and only 4 patients showed only extra-nodal disease (12\%). The most affected extra-nodal organ was the spleen $(21.2 \%)$.

According to CT-based assessment of therapeutic response (RECIST 1.1), 8 patients showed complete response (CR; 24.2\%), 18 patients showed partial response (PR; 54.5\%), 3 patients showed stationary disease (SD; 9.1\%), and 4 patients showed progressive disease (PD;
12.1\%). So, the responders (PR and $\mathrm{CR}$ ) represented $78.8 \%$ and the non-responders (SD and PD) represented 21.2\% (Tables 4 and 5). There was no significant correlation between response criteria with patient's age or sex.

According to PET-based assessment of therapeutic response (PERCIST 1.0), 18 patients showed complete metabolic response (CMR; 54.5\%), 9 patients showed partial metabolic response (PMR; 27.3\%), 2 patients showed stationary metabolic disease (SMD; 6.1\%), and 4 patients showed progressive metabolic disease (PMD; 12.1\%). So, the responders (PMR and CMR) represented 81.8\% and the non-responders (SMD and PMD) represented 18.2\% (Tables 6 and 7). There was no significant correlation between response criteria with patient's age or sex.

Thus, RECIST 1.1 and PERCIST classifications of therapeutic response were discordant in 13 patients representing $39.4 \%$ (Table 8 ). Of 11 patients classified as PR according to RECIST 1.1, ten were classified as CMR according to PERCIST 1.0 (Fig. 1) as the sum of the longest diameters' reduction of residual target lesions was more than 30\% yet showed 100\% reduction in the SULpeak, while one patient was classified as SMD according to PERCIST 1.0 (Fig. 2). Two patients were classified as

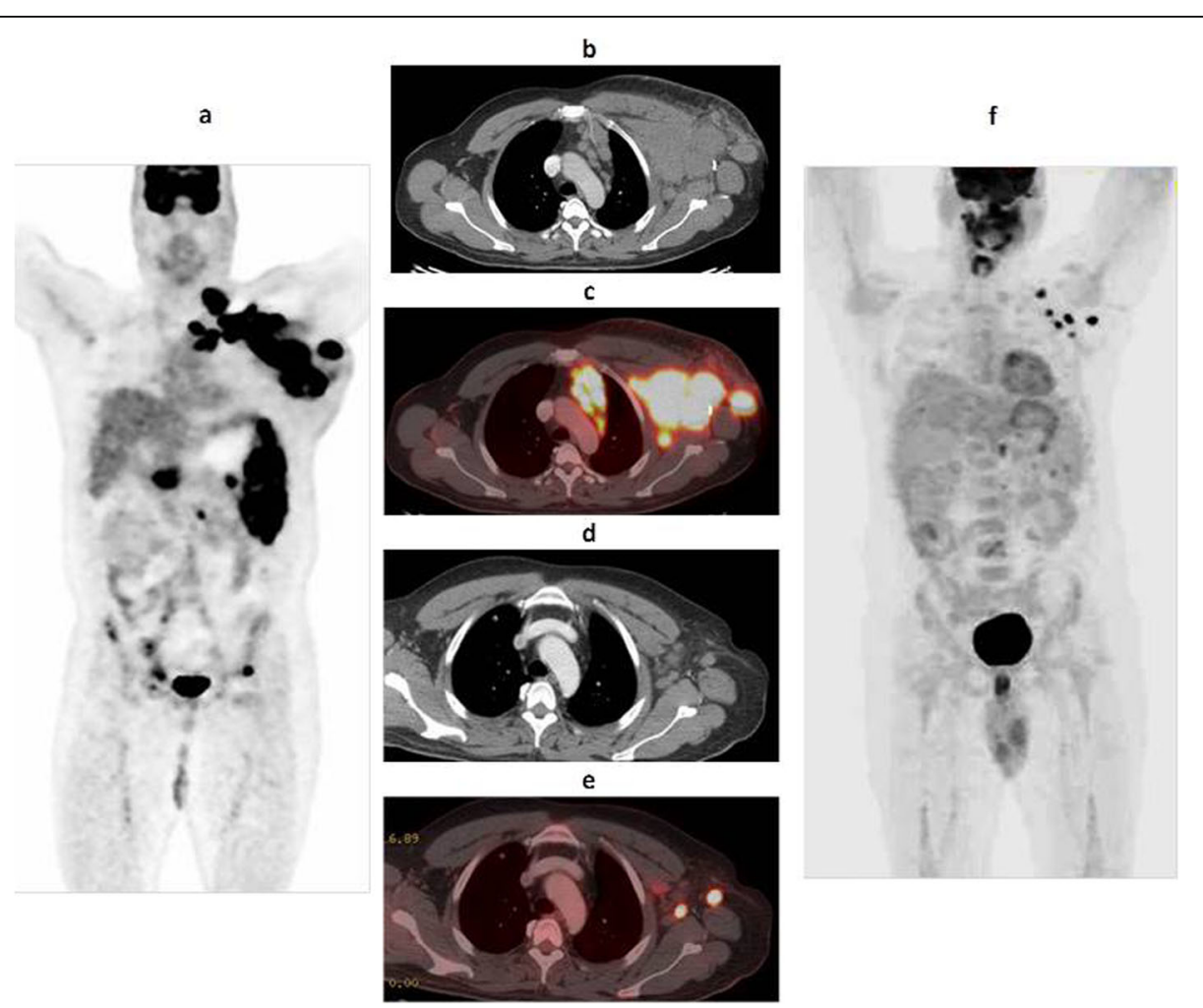

Fig. 2 A 43-year-old male patient, recently diagnosed case of T-cell NHL. Initial PET/CT study revealed hypermetabolic nodal and splenic lesions in whole body PET MIP image (a), the largest and most active lesions are seen at left axillary group as in axial CECT image (b), achieving up to 20 SUL $L_{\text {peak }}$ in corresponding fused PET/CT image (c). Follow-up PET/CT study showed residual active lesions in whole body PET MIP image (f). The left axillary nodal lesions showed size regression in axial CECT image (d) denoting PR according to RECIST 1.1, yet with almost stationary FDG

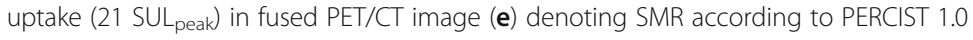


SD according to RECIST 1.1, yet, they were classified as PMR according to PERCIST 1.0 (as the decrease in the sum of the longest diameters of the target lesions was less than $30 \%$, while the decrease in the $\mathrm{SUL}_{\text {peak }}$ of the target lesions was more than 30\%). So, PERCIST 1.0based therapeutic response was upgraded in twelve patients and downgraded in one patient.

On the other hand, both RECIST 1.1 and PERCIST 1.0 classifications of therapeutic response were concordant in 20 patients representing $60.6 \%$. Eight patients (24.2\%) had CR by RECIST 1.1 and CMR by PERCIST 1.0 (Fig. 3). Seven patients had PR by RECIST 1.1 and PMR by PERCIST 1.0 (21.2\%). One patient (3\%) showed SD by RECIST 1.1 and SMD by PERCIST 1.0 (Fig. 4). Four patients presented with newly developed lesions and were classified as PD and PMD by both RECIST 1.1 and PERCIST 1.0 classifications, respectively (12.1\%).

\section{Discussion}

On the follow-up of cancer patients to evaluate response to treatment, CT was the modality of choice with RECIST criteria as a widely used and accepted tool for assessment, yet it is depending on the changes in tumoral size which may show some inter-observer variability especially in irregular lesions. Also, CT has the inability to detect the changes in activity which occurred in response to treatment [12]. It is difficult to distinguish necrotic tissue or fibrotic scar from residual tumor on CT scans [13]. Response evaluation protocols that are depending on morphological changes are still limited as changes in tumor dimensions are not true markers of therapeutic efficacy because tumor tissue consists of different components that are not all completely regressed over time [14]. This is why some studies found a discrepancy between the CT-based RECIST and the histopathological results among a significant number of the studied cases during follow-up after neoadjuvant chemotherapy [15].

So, more satisfactory methods of evaluation are needed to accurately measure tumor responses quantitatively. ${ }^{18}$ F-FDG PET thought to overcome these limitations and became a well-established quantitative method for the staging, follow-up, and detection of recurrence in patients with several malignancies $[5,11,16]$. With the development of ${ }^{18} \mathrm{~F}$ FDG PET/CT, which is integrated anatomic and metabolic imaging, a modified PET-based criteria (PERCIST) have been reported for assessing treatment response in both solid tumors and hematologic malignancies [3].

In our study, we investigated the concordance between the metabolic criteria and morphologic criteria for the assessment of end therapeutic response to chemotherapy in patients with malignant lymphoma determined using RECIST 1.1 and PERCIST 1.0 criteria.

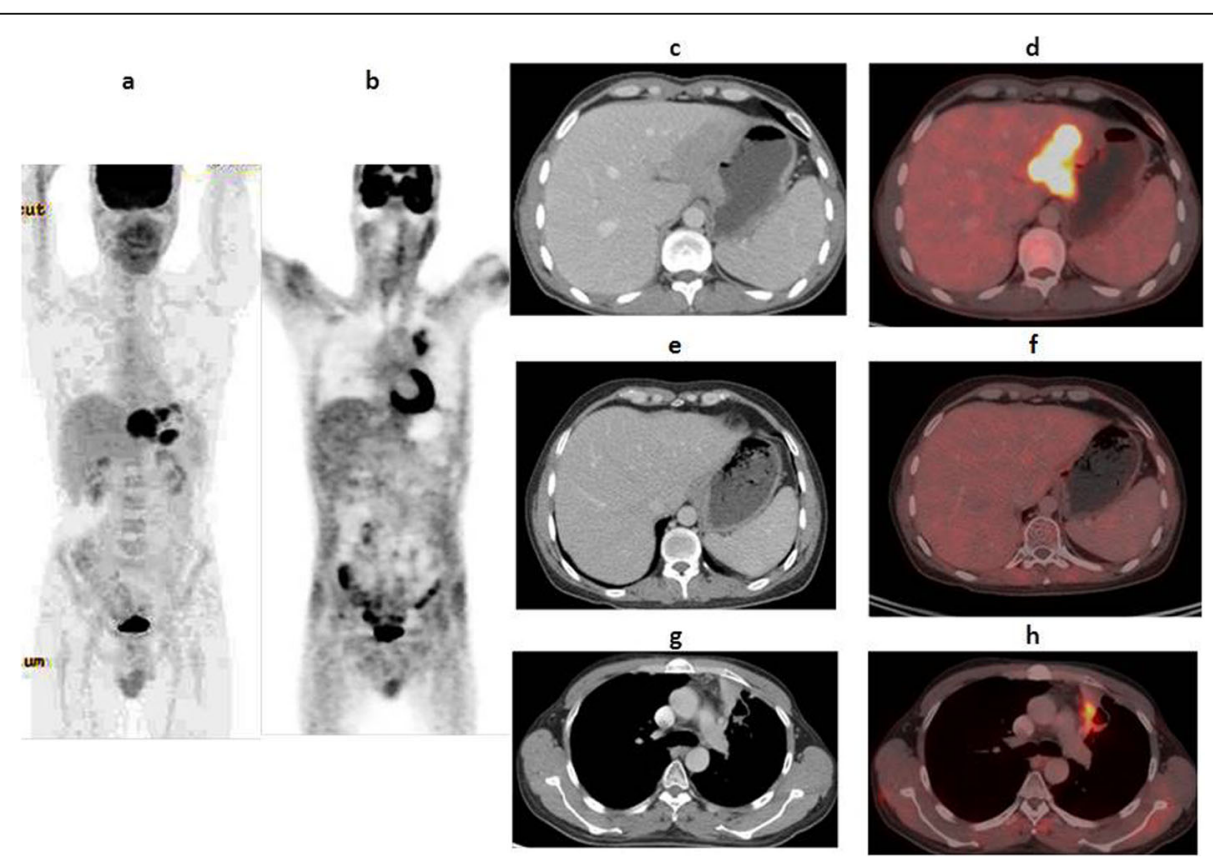

Fig. 3 A 35-year-old male patient, newly diagnosed case of gastric lymphoma. Initial PET/CT study including whole body PET MIP (a), axial CECT (c), and corresponding fused PET/CT (d) images revealed irregular hypermetabolic gastric soft mass infiltrating the related left hepatic lobe and

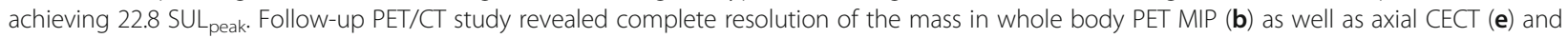
corresponding fused PET/CT (f) images denoting CR and CMR according to RECIST 1.1 and PERCIST 1.0, respectively. However, the whole body image (b) showed another newly developed metabolically active lesion at upper lobe of left lung that was a pneumonic consolidative patch in axial images $(\mathbf{g})$ and $(\mathbf{h})$. 


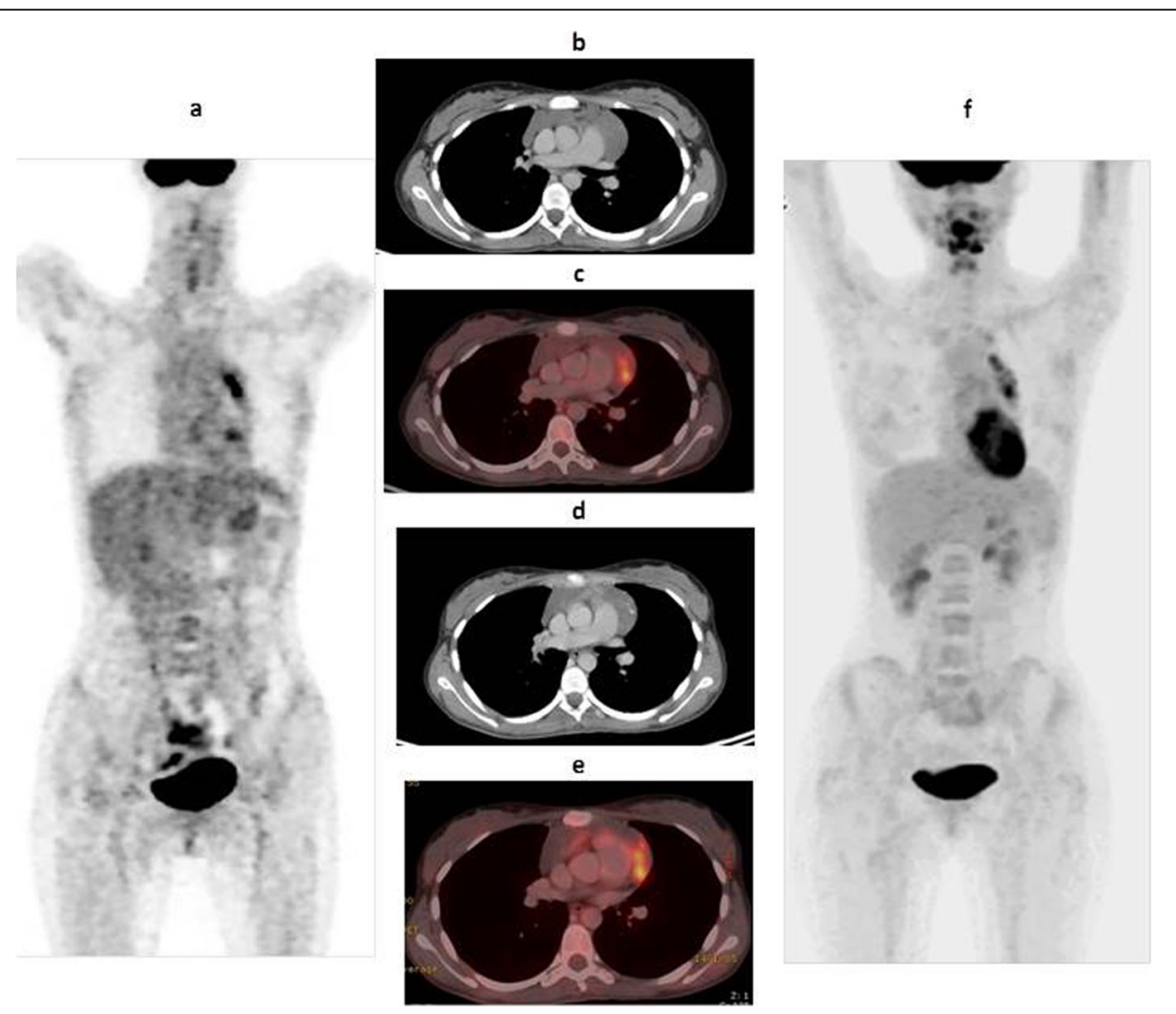

Fig. 4 A 20-year-old female patient, recently diagnosed case of HL. Initial PET/CT study revealed hypermetabolic mediastinal mass in whole body PET MIP image (a), formed of enlarged amalgamated retrosternal/prevascular mediastinal in axial CECT image (b) and achieving 5.5 SUL corresponding fused PET/CT image (c). Follow-up PET/CT study still showed the hypermetabolic mediastinal mass in whole body PET MIP image (f) that was of stationary size in axial CECT image (d) denoting SD according to RECIST 1.1, and almost showing stationary FDG uptake (6 SUL peak) in fused PET/CT image (e) denoting SMR according to PERCIST 1.0

We included 33 patients who were recently diagnosed with malignant lymphoma. Their end of treatment response was evaluated using RECIST 1.1 and PERCIST 1.0 criteria. Results showed a considerable discrepancy in the assessment of tumor responses between the morphologic criteria (RECIST 1.1) and metabolic criteria (PERCIST 1.0) with discordance in $39.4 \%$ of patients (13 patients) and $P$ value $<0.001$.

There is tendency for RECIST to downgrade the tumor response (ten patients classified as PR according to RECIST 1.1 were classified as CMR according to PERCIST 1.0, and two patients that classified as SD according to RECIST 1.1 were classified as PMR according to PERCIST 1.0). This lead to avoiding unnecessary anticancer treatments including chemotherapy or radiotherapy, which means that PERCIST 1.0 criteria were more sensitive and reliable than RECIST 1.1 for the detection of therapeutic response.

In a retrospective study conducted by Baratto et al. and compared therapeutic response in 38 patients with non-Hodgkin lymphoma by RECIST 1.1 and PERCIST criteria, evaluating both early treatment response as well as end of therapy concluded that the Deauville and
PERCIST criteria were the most reliable for predicting end-of-treatment response, reporting an accuracy of $81.6 \%$, being consistent with our results [1].

Our study results are also matched with other studies which included lymphoma and other different solid tumors. In a study done by Yanagawa et al. on 46 patients with esophageal cancer who received chemotherapy, $56.5 \%$ of patients showed discordant therapeutic response between RECIST 1.1 and PERCIST with Wilcoxon signed-rank test, $P<0.0001$ [17]. Other studies done by Ding et al. and Shang et al. which included 44 and 35 patients with non-small cell lung cancer, 34.1\% and $62.9 \%$ of patients showed discordant response after application of RECIST 1.1 and PERCIST [14, 18]. A $61.5 \%$ discordant rate was achieved by Bang et al. in a study conducted on 39 patients with colorectal cancer after targeted therapy [19]. Also, in a study done by Riedl et al. (included 65 patients with breast cancer who received therapy and evaluated with RECIST 1.1 and PERCIST criteria), a 52.3\% discordant rate was found [20]. Studies conducted by Agrawal et al. and Aras et al. included 43 and 60 patients with different types of solid tumors (breast cancer, lung cancer, PNET, head and 
neck cancer, sarcoma, non-Hodgkin lymphoma, GIT cancers, and others), $20 \%$ and $18.3 \%$ of patients showed contradictory response when evaluated using RECIST 1.1 and PERCIST criteria [21, 22].

These results mean that PERCIST is used among international observers more consistently, as it provides the needed standardization of the PET protocol. This is very important because availability of consistent criteria leads to accurate comparisons between different studies and facilitates advances in cancer treatment. Moreover, the use of computer-assisted reading application that is fully customized for use with PERCIST makes the procedure of evaluation easier and helps ensure more precise results.

There are few limitations of our study. First, the corresponding pathological results to our imaging findings has not been evaluated and further studies are needed to investigate the correlation of these findings with pathological examinations. Second, adequate follow-up of patients were not achieved to correlate our results with the patients' progression-free survival or overall survival. The main limitation was the small sample size due to the high cost of the technique, and future studies with larger number of patients may be needed to obtain more accurate results.

\section{Conclusion}

The recently applied PET/CT-based criteria (PERCIST $1.0)$ is efficient and more accurate than CT-based criteria (RECIST 1.1) to assess treatment response in patients with lymphoma, which subsequently help in decision making and affect further management of these patients.

\section{Abbreviations \\ ${ }^{18}$ F FDG: ${ }^{18}$ F-Fluorodeoxyglucose; PET/CT: Positron emission tomography/ computed tomography; HL: Hodgkin lymphoma; NHL: Non-Hodgkin Iymphoma; RECIST: Response evaluation criteria in solid tumor; PERCIST: PET response criteria in solid tumor; CR: Complete response; CMR: Complete metabolic response; PR : Partial response; PMR: Partial metabolic response; SD: Stationary disease; SMD: Stationary metabolic disease; PD: Progressive disease; PMD: Progressive metabolic disease}

\section{Acknowledgements}

Not applicable

\section{Authors' contributions}

MM carried out the PET/CT studies and collected the data. SA, AY, and AM participated in the design of the study. MM performed the statistical analysis, and SA drafted the manuscript. The authors read and approved the final manuscript.

\section{Funding}

This work has not received any funding.

\section{Availability of data and materials}

All data generated or analyzed during this study are included in this article.

\section{Ethics approval and consent to participate}

The study protocol was approved by the Research Ethics Committee (REC) of Ain Shams University, Faculty of Medicine (FMASU M D 221/2018) and written informed consent was obtained from all patients to participate in the study.

\section{Consent for publication}

Written informed consent was obtained from all patients for publication of the study

\section{Competing interests}

The authors declare that they have no competing interests.

Received: 27 March 2020 Accepted: 12 May 2020

Published online: 26 May 2020

\section{References}

1. Baratto L, Jegede O, Hong F, Kahl B, Evens A, Quon A (2016) Comparison between LUGANO, EORTC, PERCIST and IHP criteria at interim PET in patients with follicular non-Hodgkin's lymphoma. Eur J Nucl Med Mol Imaging 43(20):S30-S31

2. Maffione AM, Paolini R, Rodella E, Ambrosio C, Rampin L, Lisato LC, Rubello D (2015) Response criteria for malignant lymphoma. Nucl Med Commun 36(4):398-405

3. Moghbel MC, Kostakoglu L, Zukotynski K, Chen DL, Nadel H, Niederkohr R, Mittra E (2016) Response assessment criteria and their applications in lymphoma: part 1. J Nucl Med 57(6):928-935

4. Ali SA, Abd Elkhalek YI (2016) Added value of combined ${ }^{18}$ F-FDG PET/CT for detection of osseous metastases in cancer patients. EJRNM 47(2):453-458

5. Fletcher JW, Djulbegovic B, Soares HP et al (2008) Recommendations on the use of ${ }^{18} \mathrm{~F}$-FDG PET in oncology. J Nucl Med 49:480-508

6. Ali SA, Abd Elkhalek YI (2016) Value of integrated PET/CT in detection of hepatic metastatic deposits. EJRNM 47(2):459-465

7. Ali SA, Hamed MA (2017) The diagnostic efficacy of whole body ${ }^{18} \mathrm{~F}$ FDG PET $C T$ in detection of unexpected second primary malignancy in cancer patients. EJRNM 48(3):671-676

8. Baratto L, Davidzon G, Moghbel M, Hatami N, lagaru A, Mittra E (2018) Comparison between different PET and CT-based imaging interpretation criteria at interim imaging in patients with diffuse large B-cell lymphoma. Clin Nucl Med 43(1):1-8

9. Mansour MG, Ali SA (2016) Transarterial chemoembolization using drug eluting microspheres in refractory colorectal liver metastases with ${ }^{18} \mathrm{~F}-\mathrm{FDG}$ PET/CT follow-up to assess therapeutic response. EJRNM 47(4):1467-1472

10. Ali SA, Amin DH, Abdelkhalek YI (2020) Efficiency of whole-body ${ }^{18}$ F-FDG PET CT in detecting the cause of rising serum AFP level in post-therapeutic follow-up for HCC patients. Jpn J Radiol 38(5):472-479

11. Wahl R, Jacene H, Kasamon $Y$ et al (2009) From RECIST to PERCIST: evolving considerations for PET response criteria in solid tumors. J Nucl Med 50: 122S-150S

12. Sheikhbahaei S, Mena E, Yanamadala A et al (2017) The value of FDG PET/ $\mathrm{CT}$ in treatment response assessment, follow-up, and surveillance of lung cancer. AJR 208(2):420-433

13. Suzuki C, Jacobsson H, Hatschek T et al (2008) Radiologic measurements of tumor response to treatment: practical approaches and limitations. Radiographics 28:329-344

14. Shang J, Ling $X$, Zhang $L$ et al (2016) Comparison of RECIST, EORTC criteria and PERCIST for evaluation of early response to chemotherapy in patients with non-small-cell lung cancer. Eur J Nucl Med Mol Imaging 43:1945-1953

15. William W, Pataer A, Kalhor N et al (2013) Computed tomography RECIST assessment of histopathological response and prediction of survival in patients with resectable non-small cell lung cancer after neoadjuvant chemotherapy. J Thorac Oncol 8:222-228

16. Ali SA, Abdelkawi MM, Hussien NM (2019) Delayed post-diuretic ${ }^{18}$ F-FDG PET/CT: can it help in determination of the best clinical decision for muscle invasive UB cancer patients? EJRNM 50:111

17. Yanagawa M, Tatsumi M, Miyata $\mathrm{H}$ et al (2012) Evaluation of response to neoadjuvant chemotherapy for esophageal cancer: PET response criteria in solid tumors versus response evaluation criteria in solid tumors. J Nucl Med 53:872-880

18. Ding Q, Cheng $X$, Yang $L$ et al (2014) PET/CT evaluation of response to chemotherapy in non-small cell lung cancer: PET response criteria in solid tumors (PERCIST) versus response evaluation criteria in solid tumors (RECIST). J Thorac Dis 6:677-683 
19. Bang J, Lim Y, Paeng JC et al (2017) Comparison of quantitative methods on FDG PET/CT for treatment response evaluation of metastatic colorectal cancer. Nucl Med Mol Imaging 51:147-153

20. Riedl CC, Pinker K, Ulaner GA et al (2017) Comparison of FDG-PET/CT and contrast-enhanced $C T$ for monitoring therapy response in patients with metastatic breast cancer. Eur I Nucl Med Mol Imaging 44:1428-1437

21. Agrawal A, Purandare N, Shah S, Puranik A, Banavali S, Rangarajan V (2014) Response assessment in metronomic chemotherapy: RECIST or PERCIST. Indian J Nucl Med 29:74-80

22. Aras M, Erdil TY, Dane F et al (2016) Comparison of WHO, RECIST 1.1, EORTC, and PERCIST criteria in the evaluation of treatment response in malignant solid tumors. Nucl Med Commun 37:9-15

\section{Publisher's Note}

Springer Nature remains neutral with regard to jurisdictional claims in published maps and institutional affiliations.

\section{Submit your manuscript to a SpringerOpen ${ }^{\odot}$ journal and benefit from:}

- Convenient online submission

- Rigorous peer review

- Open access: articles freely available online

- High visibility within the field

- Retaining the copyright to your article

Submit your next manuscript at $\boldsymbol{\wedge}$ springeropen.com 